Check for updates

Cite this: RSC Adv., 2017, 7, 46321

Received 5th September 2017

Accepted 26th September 2017

DOI: $10.1039 / \mathrm{c7ra09881b}$

rsc.li/rsc-advances

\section{Regulation of coin metal substituents and cooperativity on the strength and nature of tetrel bonds $\dagger$}

\author{
Yuanxin Wei, Jianbo Cheng, Wenzuo Li and Qingzhong Li (DD* \\ $A b$ initio calculations have been performed for the tetrel-bonded dyad $M C N \cdots \mathrm{TF}_{4}(\mathrm{M}=\mathrm{Cu}, \mathrm{Ag}$, and $\mathrm{Au} ; \mathrm{T}=$ \\ $\mathrm{C}, \mathrm{Si}, \mathrm{Ge}$, and Sn). A coin metal substituent greatly strengthens the tetrel bond, depending on the nature of \\ the coin metal and tetrel atoms. The Ag substituent has the largest enhancing effect with the interaction \\ energy approaching $-16 \mathrm{kcal}^{\mathrm{mol}}{ }^{-1}$. The strength of the tetrel bond in $\mathrm{MCN} \cdots \mathrm{TF}_{4}$ can be further \\ regulated by the cooperative effect with a $\pi \cdots$ metal interaction. It is strengthened in $\mathrm{C}_{2} \mathrm{H}_{4} \cdots M C N \cdots \mathrm{TF}_{4}$ \\ but is weakened in $\mathrm{C}_{2}(\mathrm{CN})_{4} \cdots \mathrm{MCN} \cdots \mathrm{TF}_{4}$. The interaction energy of the tetrel bond amounts to about \\ $-16 \mathrm{kcal} \mathrm{mol}^{-1}$ in $\mathrm{C}_{2} \mathrm{H}_{4} \cdots \mathrm{CuCN} \cdot \mathrm{SiF}_{4}$, becoming a strong interaction. The nature of the tetrel bond is \\ changed due to the metal substituents and cooperativity.
}

\section{Introduction}

By plotting molecular electrostatic potential (MEP) maps of halogen-containing molecules, Clark et al., found a positive MEP on the outermost portion of the halogen's surface, named the $\sigma$ hole. ${ }^{1}$ This $\sigma$-hole is helpful in explaining the formation of a halogen bond and its directionality. ${ }^{2}$ Such a $\sigma$-hole is also observed on many covalently-bonded atoms of Groups IV-VI. ${ }^{3-5}$ The corresponding intermolecular interactions are called tetrel, ${ }^{6}$ pnicogen, ${ }^{7}$ and chalcogen bonds. ${ }^{8}$ These intermolecular interactions have a uniform name: $\sigma$-hole bonding. ${ }^{9}$ Very recently, Grabowski and Sokalski performed a comparative study on some Lewis acid-Lewis base complexes linked by different $\sigma$-hole bonds and proposed that they have numerous correlations similar to hydrogen-bonded systems. ${ }^{10}$ More importantly, these $\sigma$-hole bonds have similar applications with hydrogen bonds in crystal materials, chemical reactions, and biological systems. ${ }^{6,711-15}$

Recently, much attention has been paid to tetrel bonding ${ }^{16-26}$ since Bauzá et al., pointed out that it might serve as a new possible molecular linker in supramolecular materials. ${ }^{6}$ In addition, tetrel bonding is also confirmed to be important in chemical reactions ${ }^{14,15}$ and molecular recognition. ${ }^{27,28}$ Tetrel atoms are usually tetravalent in tetrel bonding, thus the formation of tetrel bonding suffers steric constraints if the tetrel atom is adjoined with steric groups. It is natural to understood that $\mathrm{TH}_{4}, \mathrm{TH}_{3} \mathrm{X}$, and $\mathrm{TF}_{4}$ (where $\mathrm{T}$ refers to a tetrel atom and $\mathrm{X}$ is an electron-withdrawing atom or group) are often used as the

The Laboratory of Theoretical and Computational Chemistry, School of Chemistry and Chemical Engineering, Yantai University, Yantai 264005, People's Republic of China. E-mail: liqingzhong1990@sina.com; Fax: +86 535 6902063; Tel: +86 5356902063

$\dagger$ Electronic supplementary information (ESI) available. See DOI: 10.1039/c7ra09881b tetrel donors in studying tetrel bonds. When a strong Lewis base attacks the tetravalent tetrel atom, the three covalent bonds facing the Lewis base are repelled to reduce steric constraints, and a trigonal bipyramid structure is finally favorable. This shows that deformation of a tetravalent tetrel molecule is crucial in stabilizing strong tetrel-bonded complexes. ${ }^{26}$

For tetrel bonds, there is a tendency to be strengthened as the $\mathrm{T}$ atom moves down this column of the periodic table since the $\sigma$-hole on the $\mathrm{T}$ atom is enlarged. ${ }^{29} \mathrm{CH}_{4}$ seldom participates in tetrel bonding due to the absence of a $\sigma$-hole on the carbon atom. However, it can do if the carbon atom binds with an electron-withdrawing atom or group. ${ }^{16}$ Scheiner performed a systematic study of factors that influence the strength of tetrel bonds. ${ }^{30}$ With $\mathrm{NH}_{3}$ as a universal Lewis base, unsubstituted $\mathrm{TH}_{4}$ molecules form the weakest tetrel bonds, and this bonding is strengthened gradually from $\mathrm{TH}_{3} \mathrm{~F}$ through $\mathrm{THF}_{3}$ to $\mathrm{TF}_{4}{ }^{30}$ Additionally, this influence is also dependent on the nature of the T atom. ${ }^{30} \mathrm{HCN}$ is a weaker Lewis base than $\mathrm{NH}_{3}$, while LiCN is a stronger Lewis base than $\mathrm{NH}_{3}$ in forming a tetrel bond due to the strong electron-donating ability of Li atom. ${ }^{14}$ This indicates that metal substituents in the Lewis bases are effective in strengthening tetrel bonds like that in halogen bonds. ${ }^{31}$

In most cases, the applications of tetrel bonds in crystal materials and molecular recognition are reached by cooperative effect with itself and other interactions. The addition of a phenyl ring to a single imidazolium perturbs the binding very little with halide anions, while placement of a second imidazolium on the benzene connector group markedly enhances binding energies. ${ }^{32}$ Some supramolecular assemblies involving lead(II) complexes have been constructed by means of tetrel bonding and other interactions. ${ }^{33-35}$ Therefore, there are many theoretical studies reported for cooperativity involving tetrel bonds. ${ }^{22,36-44} \mathrm{~F}_{2} \mathrm{CX}(\mathrm{X}=$ Se and Te) can simultaneously form a tetrel bond with the carbon 
atom and a chalcogen bond with the $\mathrm{X}$ atom, thus both interactions display anticooperativity. ${ }^{22}$ Both anion $-\pi$ and tetrel-bond interactions are enhanced in the same multicomponent complex of $\mathrm{X} \cdots$ pyrazine/1,4-dicyanobenzene $\cdots \mathrm{TH}_{3} \mathrm{~F} / \mathrm{F}_{2} \mathrm{TO} .{ }^{44}$ In all, the strength of tetrel bonding can be tuned by cooperative effect.

Interestingly, Grabowski ${ }^{\mathbf{1 4}}$ claimed that tetrel bond is not formed in $\mathrm{F}_{4} \mathrm{Si} \cdots \mathrm{NCH}$ due to the small $\mathrm{Lp}_{\mathrm{N}} \rightarrow \sigma_{\mathrm{Si}-\mathrm{F}}^{*}$ orbital interaction and negligible charge transfer. This means that the tetrel bond in $\mathrm{F}_{4} \mathrm{Si} \cdots \mathrm{NCH}$ is weak with interaction energy of $-2.8 \mathrm{kcal} \mathrm{mol}^{-1} \cdot{ }^{14}$ We plan to strengthen the tetrel bond in $\mathrm{F}_{4} \mathrm{Si} \cdots \mathrm{NCH}$ by using $\mathrm{MCN}$ ( $\mathrm{M}$ is a coin metal including $\mathrm{Cu}, \mathrm{Ag}$, and $\mathrm{Au}$ ) and we also compare the effect of different coin metals on the strength of tetrel bonding. AuCN $\cdots \mathrm{TF}_{4}(\mathrm{~T}=\mathrm{C}, \mathrm{Si}, \mathrm{Ge}$, and $\mathrm{Sn}$ ) is used to analyze the dependence of coin metal effect on the nature of the tetrel atom. To further strengthen the tetrel bond in $\mathrm{MCN} \cdot \mathrm{TF}_{4}$, we introduce a third molecule $\mathrm{C}_{2} \mathrm{H}_{4}$ to bind with the coin metal in this complex. For comparison, $\mathrm{C}_{2} \mathrm{H}_{2} \cdots \mathrm{AuCN} \cdots$ $\mathrm{SiF}_{4}$ is also studied. In the $\pi \cdots$ coin metal interaction, the $\pi$-electrons transfer from the occupied $\pi$-orbital into the empty $\sigma$-type metal orbital, while there is also a $\pi$-electron backdonation from the occupied d orbital of metal into the empty $\pi$ anti-bonding orbital. ${ }^{45}$ To regulate the role of coin metals in the $\pi \cdots$ coin metal interaction and its effect on the strength of tetrel bond, the four hydrogen atoms in $\mathrm{C}_{2} \mathrm{H}_{4}$ are replaced by strong electron-withdrawing group $\mathrm{CN}$.

\section{Theoretical methods}

The structures of complexes and monomers were fully optimized using the Moller-Plesset perturbation (MP2) theory. The basis set adopted was aug-cc-pVTZ for the respective atoms except Sn and coin metal atoms, for which aug-cc-pVTZ-PP was used to account for relativistic effects. ${ }^{\mathbf{4 6}}$ Harmonic frequency calculations at the same level were carried out to confirm that the structures obtained corresponded to energy minima. The interaction energies using supermolecular method (difference between the energy of the complex and the energies of the monomers with their geometries within the complex) were corrected for the basis set superposition error (BSSE) by the counterpoise method of Boys and Bernardi. ${ }^{47}$ All calculations were performed using the Gaussian 09 package. ${ }^{48}$

The MEP analysis at the molecular surface was performed by the Wave Function Analysis-Surface Analysis Suite (WFA-SAS) program. ${ }^{49}$ The bonding characteristics were analyzed at the MP2/aug-cc-pVDZ(PP) level by means of Atoms-in-Molecules (AIM) theory $^{50}$ with the help of AIM 2000 software. ${ }^{51}$ The second-order perturbation energy and charge transfer was obtained at the HF/aug-cc-pVTZ level with natural bond orbital (NBO) method $^{52}$ implemented in Gaussian 09. Interaction energy was decomposed using the LMOEDA method ${ }^{53}$ at the same level by the GAMESS program. ${ }^{54}$

\section{Results and discussion}

\subsection{Substituent effect of coin metal}

Fig. 1 shows the diagrams of some dyads studied, and the corresponding interaction energies are given in Table 1 . The
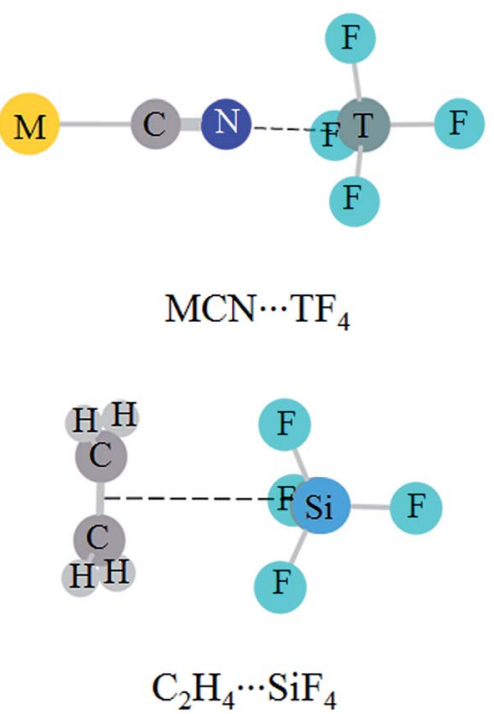

Fig. 1 Structures of $\mathrm{MCN} \cdots \mathrm{TF}_{4}$ and $\mathrm{C}_{2} \mathrm{H}_{4} \cdots \mathrm{SiF}_{4}$.

Table 1 Interaction energy corrected for $\operatorname{BSSE}\left(\Delta E, \mathrm{kcal} \mathrm{mol}^{-1}\right)$ and binding distance $(R, \AA)$ in the tetrel-bonded dyads ${ }^{a}$

\begin{tabular}{lllll}
\hline Dyads & $\Delta E$ & $\Delta \Delta E$ & $\%$ & $R$ \\
\hline AuCN $\cdots \mathrm{CF}_{4}$ & $-1.32(-1.09)$ & -0.23 & 21.10 & 3.3268 \\
AuCN $\cdots \mathrm{SiF}_{4}$ & $-4.95(-3.45)$ & -1.50 & 43.48 & 2.8598 \\
$\mathrm{AuCN} \cdots \mathrm{GeF}_{4}$ & $-19.60(-10.70)$ & -8.90 & 83.18 & 2.1818 \\
$\mathrm{AuCN} \cdots \mathrm{SnF}_{4}$ & $-26.96(-12.94)$ & -14.02 & 108.35 & 2.2343 \\
$\mathrm{AgCN} \cdots \mathrm{SiF}_{4}$ & -15.80 & -12.35 & 357.97 & 2.2812 \\
$\mathrm{CuCN}^{2} \cdots \mathrm{SiF}_{4}$ & -6.12 & -2.67 & 77.39 & 2.6338 \\
$\mathrm{C}_{2} \mathrm{H}_{4} \cdots \mathrm{SiF}_{4}$ & -1.93 & - & - & 3.4880 \\
$\mathrm{C}_{2} \mathrm{H}_{4} \cdots \mathrm{SiH}_{3} \mathrm{~F}$ & -2.68 & - & - & 3.2473
\end{tabular}

${ }^{a}$ Note: data in parentheses are from $\mathrm{HCN} \cdots \mathrm{TF}_{4}$ dyads. $\Delta \Delta E$ is the difference of $\Delta E$ in between $\mathrm{MCN} \cdots \mathrm{TF}_{4}$ dyads and the corresponding HCN dyads. $\%$ is the percentage of $\Delta \Delta E$ to the $\Delta E$ of $\mathrm{HCN} \cdots \mathrm{TF}_{4}$ dyads.

strength of tetrel bond has great dependence on the nature of tetrel atom since its interaction energy extensively varies from $-1.32 \mathrm{kcal} \mathrm{mol}{ }^{-1}$ in $\mathrm{AuCN} \cdots \mathrm{CF}_{4}$ to $-26.96 \mathrm{kcal} \mathrm{mol}^{-1}$ in AuCN $\cdots \mathrm{SnF}_{4}$. Clearly, the interaction energy of tetrel bond is more negative with the increase of the tetrel atomic mass, consistent with the magnitude of $\sigma$-hole on the tetrel atom (Fig. 2). Compared with $\mathrm{HCN} \cdots \mathrm{TF}_{4}$, the tetrel bond is stronger in $\mathrm{AuCN} \cdot \mathrm{TF}_{4}$ with the more negative interaction energy. The electron-donating nature of metal atom results in an increase of the negative MEP on the nitrogen atom in MCN relative to $\mathrm{HCN}$ (Fig. 2) and thus $\mathrm{MCN}$ forms a stronger tetrel bond with $\mathrm{TF}_{4}$ than HCN. It is obvious that the enhancing effect of coin metal on the tetrel bond is related with the nature of the tetrel atom. Generally, the heavier the tetrel atom, the larger the enhancing effect of coin metal on the tetrel bond. The interaction energy of tetrel bond in AuCN $\cdots \mathrm{SnF}_{4}$ is more than doubled, becoming a very strong tetrel bond. On the other hand, the enhancing effect of coin metal is also dependent on the nature of coin metal. The increased percentage of tetrel bonding interaction energy is larger in the order $\mathrm{Au}<\mathrm{Cu}<\mathrm{Ag}$. The $\mathrm{Ag}$ substituent makes the interaction energy of tetrel bond increase from 


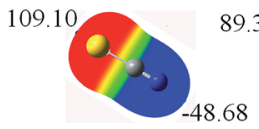

$\mathrm{AuCN}$

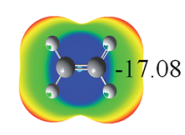

$\mathrm{C}_{2} \mathrm{H}_{4}$
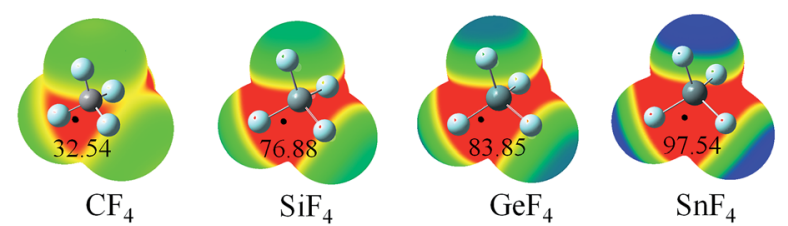

Fig. 2 MEP maps of the monomers studied, color ranges, in $\mathrm{kcal} \mathrm{mol}^{-1}$, are: red, greater than 9.5; yellow, between 9.5 and 0 ; green, between 0 and -9.5 ; blue, smaller than -9.5 .

$-3.45 \mathrm{kcal} \mathrm{mol}^{-1}$ in $\mathrm{HCN}^{\cdots} \mathrm{SiF}_{4}$ to $-15.80 \mathrm{kcal} \mathrm{mol}^{-1}$ in $\mathrm{AgCN} \cdots$ $\mathrm{SiF}_{4}$. Clearly, a strong tetrel bond is formed in $\mathrm{AgCN} \cdots \mathrm{SiF}_{4}$. Moreover, the negative MEP on the nitrogen atom is largest in AgCN and smallest in AuCN (Fig. 2). Au has the greatest electronegativity among three coin metal elements, thus its electron-donating power is smallest. Additionally, Au-CN bears strong covalence interaction, ${ }^{55}$ which also reduces the negative charge density on the nitrogen atom. However, $\mathrm{Ag}-\mathrm{CN}$ bears stronger ionic interaction than $\mathrm{Au}-\mathrm{CN},{ }^{55}$ which is partly responsible for the larger negative MEP on the nitrogen atom of AgCN. For $\mathrm{HCN} \cdots \mathrm{SiF}_{4}$, our value $\left(-3.45 \mathrm{kcal} \mathrm{mol}^{-1}\right)$ of interaction energy is more negative than that in the previous value $\left(-2.8 \mathrm{kcal} \mathrm{\textrm {mol } ^ { - 1 }}\right)^{\mathbf{1 4}}$ since our calculations were obtained on base of the geometries of the monomers in the complexes. This shows that deformation has some important contributions to the stability of tetrel-bonded complexes.

The $\mathrm{N} \cdots \mathrm{C}$ distance in AuCN $\cdots \mathrm{CF}_{4}$ is $3.3268 \AA$, which almost equals to the sum of the van der Waals ( $\mathrm{vdW}$ ) radii of both atoms. Although both molecules arrange in a line in AuCN $\cdots$ $\mathrm{CF}_{4}$, this complex can be taken as a van der Waals complex. The separation in other complexes is smaller than the sum of vdW Radii of the corresponding atoms. The $\mathrm{N} \cdots \mathrm{Si}$ distance in $\mathrm{MCN} \cdots \mathrm{SiF}_{4}$ is smaller in the sequence AuCN $>\mathrm{CuCN}>\mathrm{AgCN}$, consistent with the change of the interaction energy.

Fig. 3 is the AIM diagrams of $\mathrm{MCN} \cdots \mathrm{TF}_{4}$. In the weak complexes of AuCN $\cdots \mathrm{CF}_{4}$ and $\mathrm{AuCN} \cdots \mathrm{SiF}_{4}$, the tetrel bond is characterized with three $\mathrm{N} \cdots \mathrm{F}$ paths. The $\mathrm{N} \cdots \mathrm{F}$ path is linear in AuCN $\cdots \mathrm{CF}_{4}$ but is curve in AuCN $\cdots \mathrm{SiF}_{4}$. The similar path is also found in $\mathrm{CuCN}^{\cdots} \mathrm{SiF}_{4}$. When the tetrel bond is strong enough, the $\mathrm{N} \cdots \mathrm{F}$ paths are changed to be a linear $\mathrm{N} \cdots \mathrm{T}$ path in $\mathrm{AgCN} \cdots$ $\mathrm{SiF}_{4}, \mathrm{AuCN} \cdots \mathrm{GeF}_{4}$, and $\mathrm{AuCN} \mathrm{SnF}_{4}$. Three fluorine atoms in the strong tetrel-bonded complexes are far away from the nitrogen atom in MCN. The topological parameters at these paths are listed in Table 2 . The electron density at the $\mathrm{N} \cdots \mathrm{C} \mathrm{BCP}$ is very small in AuCN $\cdots \mathrm{CF}_{4}$. Besides, the charge transfer and orbital interaction are also very small in this complex (Table 3). Thus the interaction in $\mathrm{AuCN} \cdots \mathrm{CF}_{4}$ is not a tetrel bond. The

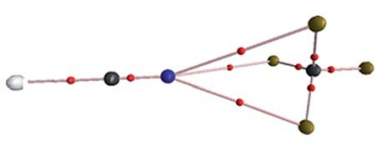

$\mathrm{AuCN} \cdots \mathrm{CF}_{4}$

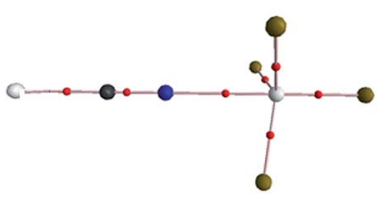

$\mathrm{AuCN} \cdots \mathrm{GeF}_{4}$

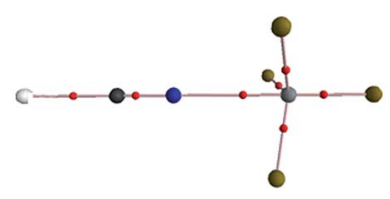

$\mathrm{AgCN} \cdots \mathrm{SiF}_{4}$
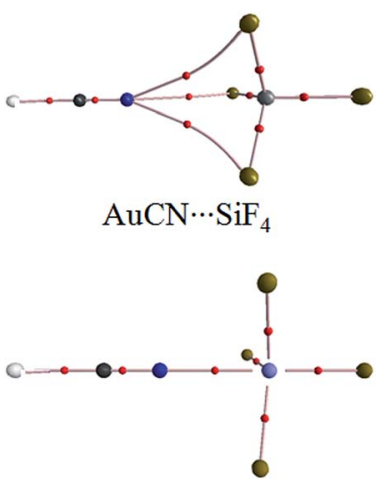

$\mathrm{AuCN} \cdots \mathrm{SnF}_{4}$

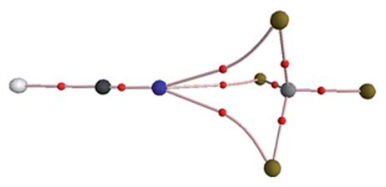

$\mathrm{CuCN} \cdots \mathrm{SiF}_{4}$
Fig. 3 AlM diagrams of $\mathrm{MCN} \cdots \mathrm{TF}_{4}$.

Table 2 Electron density $\left(\rho_{\mathrm{b}}, \mathrm{au}\right)$, Laplacian $\left(\nabla^{2} \rho_{\mathrm{b}}, \mathrm{au}\right)$, kinetic energy density $\left(G_{b}, a u\right)$, potential energy density $\left(V_{b}, a u\right)$, and total energy density $\left(H_{\mathrm{b}}, \mathrm{au}\right)$ at the intermolecular BCP in the tetrel-bonded dyads ${ }^{a}$

\begin{tabular}{llllll}
\hline Dyads & $\rho_{\mathrm{b}}$ & $\nabla^{2} \rho_{\mathrm{b}}$ & $G_{\mathrm{b}}$ & $V_{\mathrm{b}}$ & $H_{\mathrm{b}}$ \\
\hline AuCN $\cdots \mathrm{CF}_{4}$ & 0.0036 & 0.0270 & 0.0047 & -0.0038 & 0.0010 \\
AuCN $\cdots \mathrm{SiF}_{4}$ & 0.0108 & 0.0438 & 0.0109 & -0.0070 & 0.0040 \\
AuCN $\cdots \mathrm{GeF}_{4}$ & 0.0527 & 0.1853 & 0.0573 & -0.0683 & -0.0110 \\
$\mathrm{AuCN} \cdots \mathrm{SnF}_{4}$ & 0.0600 & 0.2805 & 0.0736 & -0.0771 & -0.0035 \\
$\mathrm{AgCN} \cdots \mathrm{SiF}_{4}$ & 0.0314 & 0.1024 & 0.0319 & -0.0382 & -0.0063 \\
$\mathrm{CuCN} \cdots \mathrm{SiF}_{4}$ & 0.0166 & 0.0524 & 0.0152 & -0.0153 & -0.0001 \\
$\mathrm{C}_{2} \mathrm{H}_{4} \cdots \mathrm{SiF}_{4}$ & 0.0057 & 0.0208 & 0.0044 & -0.0035 & 0.0010
\end{tabular}

${ }^{a}$ Note: the bond path is $\mathrm{N} \cdots \mathrm{F}$ in $\mathrm{AuCN} \cdots \mathrm{CF}_{4}, \mathrm{AuCN} \cdots \mathrm{SiF}_{4}$, and $\mathrm{CuCN} \cdots$ $\mathrm{SiF}_{4}, \mathrm{~N} \cdots \mathrm{T}$ in AuCN $\cdots \mathrm{GeF}_{4}, \mathrm{AuCN}^{\cdots} \mathrm{SnF}_{4}$, and $\mathrm{AgCN}^{\cdots} \cdot \mathrm{SiF}_{4}$, and $\mathrm{C} \cdots \mathrm{F}$ in $\mathrm{C}_{2} \mathrm{H}_{4} \cdots \mathrm{SiF}_{4}$. All are average values for the $\mathrm{N} \cdots \mathrm{F}$ and $\mathrm{C} \cdots \mathrm{F}$ paths.

electron density at the $\mathrm{N} \cdots \mathrm{Si} \mathrm{BCP}$ is increased in $\mathrm{AuCN} \cdots \mathrm{SiF}_{4}$, and its Laplacian and energy density are positive. So the tetrel bond in $\mathrm{AuCN}^{-\mathrm{SiF}_{4}}$ is a purely close-shell interaction according to the classification for intermolecular interactions by Arnold and Oldfield. ${ }^{56}$ With the enhancement of tetrel bond, the electron density at the $\mathrm{N} \cdots \mathrm{T}$ BCP grows up and the similar result is found for the corresponding Laplacian. At the same time, the energy density is changed to be negative. These results show that the tetrel bond is a partially covalent interaction in $\mathrm{CuCN} \cdots$ $\mathrm{SiF}_{4}, \mathrm{AgCN} \cdots \mathrm{SiF}_{4}, \mathrm{AuCN} \cdots \mathrm{GeF}_{4}$, and $\mathrm{AuCN} \cdots \mathrm{SnF}_{4}$.

The charge transfer in AuCN $\cdots \mathrm{CF}_{4}$ is not only very small but also it moves from $\mathrm{CF}_{4}$ to AuCN. This further confirms no formation of a tetrel bond in $\mathrm{AuCN} \cdots \mathrm{CF}_{4}$. In other complexes, the charge transfer moves from $\mathrm{MCN}$ to $\mathrm{TF}_{4}$. The charge transfer in $\mathrm{AuCN}^{\cdots} \mathrm{SiF}_{4}$ is still small and the single $\mathrm{Lp}_{\mathrm{N}} \rightarrow \sigma_{\mathrm{T}-\mathrm{F}}^{*}$ orbital interaction is not large. Thus this charge transfer interaction has a small contribution to the enhancement of tetrel bond in AuCN $\cdots \mathrm{SiF}_{4}$. The charge transfer and orbital interaction have 
Table 3 Charge transfer $\left(Q_{C T}\right.$, e) and second-order perturbation energy $\left(E^{(2)}, \mathrm{kcal} \mathrm{mol}^{-1}\right)$ due to the four $L \mathrm{p}_{\mathrm{N}} \rightarrow \sigma_{\mathrm{T}-\mathrm{F}}^{*}$ orbital interactions in the tetrel-bonded dyads ${ }^{a}$

\begin{tabular}{lll}
\hline Dyads & $Q_{\mathrm{CT}}$ & $E^{(2)}$ \\
\hline $\mathrm{AuCN} \cdots \mathrm{CF}_{4}$ & 0.0015 & 0.09 \\
$\mathrm{AuCN} \cdots \mathrm{SiF}_{4}$ & -0.0010 & 3.23 \\
$\mathrm{AuCN} \cdots \mathrm{GeF}_{4}$ & -0.1001 & 72.17 \\
$\mathrm{AuCN} \cdots \mathrm{SnF}_{4}$ & -0.1090 & 82.27 \\
$\mathrm{AgCN} \cdots \mathrm{SiF}_{4}$ & -0.0616 & 40.16 \\
$\mathrm{CuCN} \cdots \mathrm{SiF}_{4}$ & -0.0113 & - \\
$\mathrm{C}_{2} \mathrm{H}_{4} \cdots \mathrm{SiF}_{4}$ & -0.0006 & 0.97
\end{tabular}

${ }^{a}$ Note: $Q_{\mathrm{CT}}$ is the sum of charge on all atoms of $\mathrm{TF}_{4} \cdot E^{(2)}$ corresponds to the $\pi_{\mathrm{C}=\mathrm{C}} \rightarrow \sigma_{\mathrm{T}-\mathrm{F}}^{*}$ orbital interactions. $E^{(2)}$ in $\mathrm{CuCN}^{*} \mathrm{SiF}_{4}$ is not shown owing to the abnormal value in the NBO analysis.

a larger increase in $\mathrm{AgCN} \cdots \mathrm{SiF}_{4}$ and $\mathrm{CuCN} \cdots \mathrm{SiF}_{4}$, indicating that charge transfer contribution cannot be ignored in strengthening the tetrel bond. The charge transfer amounts to about $0.1 \mathrm{e}$ in $\mathrm{AuCN} \cdots \mathrm{GeF}_{4}$ and $\mathrm{AuCN} \cdots \mathrm{SnF}_{4}$, and the corresponding orbital interaction is also very large.

The weak interaction in AuCN $\cdots \mathrm{CF}_{4}$ is still dominated by electrostatic energy and dispersion energy is more than half of electrostatic energy (Table 4). In $\mathrm{AuCN} \cdot \mathrm{SiF}_{4}$, electrostatic energy has a prominent increase but dispersion energy is almost not changed with respect to $A u C N \cdots C_{4}$. The easier polarization of silicon atom leads to a relatively large increase of polarization energy in $\mathrm{AuCN}^{\cdots} \mathrm{SiF}_{4}$. For the strong tetrel bond in AuCN $\cdots \mathrm{GeF}_{4}$ and $\mathrm{AuCN} \cdots \mathrm{SnF}_{4}$, electrostatic energy is very large $\left(>-50 \mathrm{kcal} \mathrm{mol}^{-1}\right)$, and polarization energy is more than half of electrostatic energy. The relatively large polarization energy is mainly responsible for the deformation of $\mathrm{TF}_{4}$ in $\mathrm{AuCN} \cdots \mathrm{GeF}_{4}$ and $\mathrm{AuCN} \cdots \mathrm{SnF}_{4} \cdot{ }^{54}$ The similar result is found in $\mathrm{AgCN}^{\cdots} \mathrm{SiF}_{4}$. The contribution of polarization energy relative to that of electrostatic energy in $\mathrm{CuCN} \cdots \mathrm{SiF}_{4}$ is smaller than that in $\mathrm{AgCN} \cdots$ $\mathrm{SiF}_{4}$. The interaction energies in Tables 1 and 4 are almost equal each other for most complexes with an exception in CuCN $\cdots$ $\mathrm{SiF}_{4}$, where a difference of $2 \mathrm{kcal} \mathrm{mol}^{-1}$ is found. The main reason is that dispersion energy is obtained by the difference of MP2 and $\operatorname{CCSD}(\mathrm{T})$ energies. ${ }^{54}$ The strong tetrel bond in AuCN $\cdots$ $\mathrm{GeF}_{4}$ and $\mathrm{AuCN} \cdots \mathrm{SnF}_{4}$ brings out a positive dispersion energy, which is primarily caused by the difference in the intra- and intermolecular correlation energy on going from noninteracting to interacting molecules. ${ }^{\mathbf{4 4}}$

Table 4 Electrostatic $\left(E^{\mathrm{ele}}\right)$, exchange $\left(E^{\mathrm{ex}}\right)$, repulsion $\left(E^{\text {rep }}\right)$, polarization $\left(E^{\mathrm{pol}}\right)$, dispersion $\left(E^{\text {disp }}\right)$ energies, and total interaction energy $(\Delta E)$. All are in $\mathrm{kcal} \mathrm{mol}^{-1}$

\begin{tabular}{lllrlll}
\hline Dyads & $E^{\text {ele }}$ & \multicolumn{1}{l}{$E^{\text {ex }}$} & \multicolumn{1}{c}{$E^{\text {rep }}$} & $E^{\text {pol }}$ & $E^{\text {disp }}$ & \multicolumn{1}{l}{$\Delta E$} \\
\hline AuCN $\cdots \mathrm{CF}_{4}$ & -1.89 & -2.82 & 4.87 & -0.40 & -1.09 & -1.33 \\
AuCN $\cdots \mathrm{SiF}_{4}$ & -10.64 & -11.86 & 21.48 & -2.67 & -1.30 & -4.99 \\
AuCN $\cdots \mathrm{GeF}_{4}$ & -50.58 & -56.10 & 113.75 & -27.93 & 1.17 & -19.69 \\
$\mathrm{AuCN} \cdots \mathrm{SnF}_{4}$ & -52.16 & -53.59 & 107.96 & -33.03 & 3.75 & -27.08 \\
$\mathrm{AgCN} \cdots \mathrm{SiF}_{4}$ & -39.56 & -46.01 & 89.66 & -18.81 & -1.41 & -16.13 \\
$\mathrm{CuCN} \cdots \mathrm{SiF}_{4}$ & -18.72 & -21.16 & 39.31 & -5.90 & -1.66 & -8.12 \\
$\mathrm{C}_{2} \mathrm{H}_{4} \cdots \mathrm{SiF}_{4}$ & -4.54 & -7.22 & 12.96 & -0.68 & -2.44 & -1.92 \\
$\mathrm{C}_{2} \mathrm{H}_{4} \cdots \mathrm{SiH}_{3} \mathrm{~F}$ & -5.32 & -12.4 & 20.7 & -1.99 & -3.71 & -2.72
\end{tabular}

The interaction energy at the same level is $-8.13,-8.46$, and -6.77 kcal mol ${ }^{-1}$ in $\mathrm{CuCN} \cdots \mathrm{ClF}, \mathrm{AgCN} \cdots \mathrm{ClF}$, and $\mathrm{AuCN} \cdots \mathrm{ClF}$, respectively. ${ }^{57}$ The interaction energy is $-6.12,-15.80$, and -4.95 kcal mol ${ }^{-1}$ in $\mathrm{CuCN}^{\circ} \cdot \mathrm{SiF}_{4}, \mathrm{AgCN} \cdots \mathrm{SiF}_{4}$, and AuCN $\cdots \mathrm{SiF}_{4}$, respectively. A comparative analysis indicates that the dependence of tetrel bond on the coin metal is larger than that for the halogen bond. It is mainly due to the easier polarization of silicon than chlorine caused by the smaller electronegativity and bigger atomic radius of the silicon atom. The Ag substituent causes the interaction energy of halogen bond increased by $\sim 63 \%$ with respect to $-5.19 \mathrm{kcal} \mathrm{mol}^{-1}$ in $\mathrm{HCN} \cdots \mathrm{ClF},{ }^{58}$ while this atom strengthens the interaction energy of tetrel bond with $358 \%$. Obviously, the $\mathrm{Ag}$ substituent is very efficient in enhancing the strength of tetrel bond.

It was demonstrated that $\mathrm{C}_{2} \mathrm{H}_{4}$ molecule acts as the $\pi$-electron donor to form a $\pi$-tetrel bond with $\mathrm{SiH}_{3} \mathrm{~F}$ and the corresponding interaction energy is $-2.63 \mathrm{kcal} \mathrm{mol}^{-1} .{ }^{59}$ When $\mathrm{SiF}_{4}$ acts as the $\sigma$-hole donor in the $\pi$-tetrel bond, the interaction energy is $-1.93 \mathrm{kcal} \mathrm{mol}^{-1}$, which is smaller than that in $\mathrm{C}_{2} \mathrm{H}_{4} \cdots \mathrm{SiH}_{3} \mathrm{~F}$. However, the $\sigma$-hole on the silicon atom of $\mathrm{SiF}_{4}$ is larger than that of $\mathrm{SiH}_{3} \mathrm{~F}$. This inconsistence is mainly attributed to the nonzero dipole moment of $\mathrm{SiH}_{3} \mathrm{~F}$, which can greatly polarize the $\mathrm{C}_{2} \mathrm{H}_{4}$ molecule. In addition, the repulsion force between the $\pi$ electrons of $\mathrm{C}_{2} \mathrm{H}_{4}$ and three fluorine atoms of $\mathrm{SiF}_{4}$ has some contribution to this inconsistence. For the weak $\pi$-tetrel bond in $\mathrm{C}_{2} \mathrm{H}_{4} \cdots \mathrm{SiF}_{4}$, both charge transfer and orbital interaction are very small, but dispersion energy is relatively large enough not to be ignored.

\subsection{Cooperative effects}

Fig. 4 shows the structures of triads, where both a tetrel bond and a $\pi \cdots$ metal interaction coexist. The interaction in $\mathrm{C}_{2} \mathrm{H}_{4} \cdots$ AuCN is very strong $\left(>-50 \mathrm{kcal} \mathrm{mol}{ }^{-1}\right) .{ }^{57}$ Here we plan to strengthen the tetrel bond by cooperativity with a strong $\pi \cdots$ metal interaction. The weak interaction strength is almost not changed in $\mathrm{C}_{2} \mathrm{H}_{4} \cdots \mathrm{AuCN} \cdots \mathrm{CF}_{4}$. This implies that a van der Waals interaction is not strengthened prominently even in the presence of a very strong interaction. In $\mathrm{C}_{2} \mathrm{H}_{4} \cdots \mathrm{MCN} \cdots \mathrm{TF}_{4}$ ( $\mathrm{T}=\mathrm{Si}, \mathrm{Ge}$, and $\mathrm{Sn}$ ), the tetrel bond is further strengthened, evidenced by the shorter binding distance and the more negative interaction energy (Table 5). The increase of interaction energy is related with the nature of coin metal and tetrel atom in $\mathrm{C}_{2} \mathrm{H}_{4} \cdots \mathrm{MCN} \cdots \mathrm{TF}_{4}$, and its increase is larger in the order AuCN $<$ $\mathrm{AgCN}<\mathrm{CuCN}$ and $\mathrm{CF}_{4}<\mathrm{SnF}_{4}<\mathrm{SiF}_{4}<\mathrm{GeF}_{4}$. The former order is like that in halogen bonds. ${ }^{56}$ The $\mathrm{N} \cdots$ Si binding distance is shortened up to about $0.4 \AA$ in $\mathrm{C}_{2} \mathrm{H}_{4} \cdots \mathrm{CuCN} \cdots \mathrm{SiF}_{4}$, and the interaction energy has the largest increase $\left(-9.60 \mathrm{kcal} \mathrm{mol}^{-1}\right)$ in this triad. The interaction energy of tetrel bond amounts to $-7.12 \mathrm{kcal} \mathrm{mol}^{-1}$ in $\mathrm{C}_{2} \mathrm{H}_{4} \cdots \mathrm{AuCN} \cdots \mathrm{SiF}_{4}$, where the strength of tetrel bond is doubled under the combinative influence of metal substituent and cooperativity. The interaction energy of tetrel bond is up to $-15.72 \mathrm{kcal} \mathrm{mol}^{-1}$ in $\mathrm{C}_{2} \mathrm{H}_{4} \cdots \mathrm{CuCN} \cdots \mathrm{SiF}_{4}$, where the tetrel bond varies from a moderate one $\left(\mathrm{CuCN} \cdot \mathrm{SiF}_{4}\right)$ to a strong one. The tetrel bond in $\mathrm{C}_{2} \mathrm{H}_{2} \cdots \mathrm{AuCN} \cdots \mathrm{SiF}_{4}$ has a similar variation with that in $\mathrm{C}_{2} \mathrm{H}_{4} \cdots \mathrm{AuCN} \cdots \mathrm{SiF}_{4}$. This indicates that the $\mathrm{N} \cdots \mathrm{Si}$ tetrel bond is greatly enhanced by 

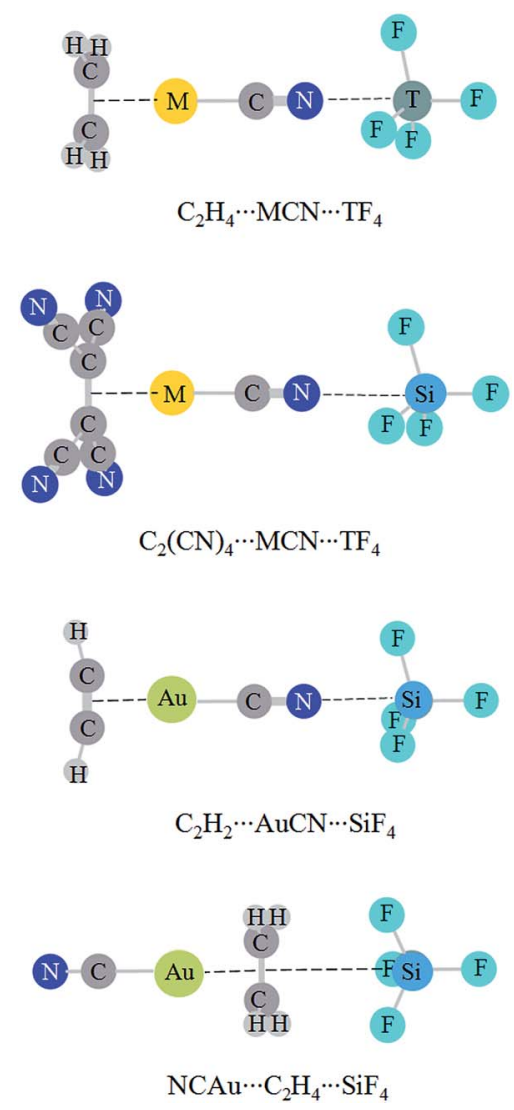

Fig. 4 Structures of triads studied.

Table 5 Binding distance $\left(R_{\mathrm{TB}}, \AA\right)$ and interaction energy $\left(\Delta E_{\mathrm{TB}},-\right.$ kcal mol${ }^{-1}$ ) of tetrel bond in the triads and their difference $(\Delta)$ relative to the corresponding dyads

\begin{tabular}{lllll}
\hline Triads & $R_{\mathrm{TB}}$ & $\Delta R_{\mathrm{TB}}$ & $\Delta E_{\mathrm{TB}}$ & $\Delta \Delta E_{\mathrm{TB}}$ \\
\hline $\mathrm{C}_{2} \mathrm{H}_{4} \cdots \mathrm{AuCN} \cdots \mathrm{CF}_{4}$ & 3.3119 & -0.0149 & -1.34 & -0.02 \\
$\mathrm{C}_{2} \mathrm{H}_{4} \cdots \mathrm{AuCN} \cdots \mathrm{SiF}_{4}$ & 2.5919 & -0.2679 & -7.12 & -2.17 \\
$\mathrm{C}_{2} \mathrm{H}_{4} \cdots \mathrm{AuCN} \cdots \mathrm{GeF}_{4}$ & 2.1169 & -0.0649 & -22.27 & -2.67 \\
$\mathrm{C}_{2} \mathrm{H}_{4} \cdots \mathrm{AuCN} \cdots \mathrm{SnF}_{4}$ & 2.2050 & -0.0293 & -28.34 & -1.38 \\
$\mathrm{C}_{2} \mathrm{H}_{4} \cdots \mathrm{AgCN} \cdots \mathrm{SiF}_{4}$ & 2.1415 & -0.1397 & -22.23 & -6.43 \\
$\mathrm{C}_{2} \mathrm{H}_{4} \cdots \mathrm{CuCN} \cdots \mathrm{SiF}_{4}$ & 2.2129 & -0.4209 & -15.72 & -9.60 \\
$\mathrm{C}_{2}(\mathrm{CN})_{4} \cdots \mathrm{AuCN} \cdots \mathrm{SiF}_{4}$ & 2.9541 & 0.0943 & -4.41 & 0.54 \\
$\mathrm{C}_{2}(\mathrm{CN})_{4} \cdots \mathrm{AgCN}^{2} \cdots \mathrm{SiF}_{4}$ & 2.8102 & 0.5290 & -6.37 & 9.43 \\
$\mathrm{C}_{2}(\mathrm{CN})_{4} \cdots \mathrm{CuCN} \cdots \mathrm{SiF}_{4}$ & 2.9483 & 0.3145 & -3.31 & 2.81 \\
$\mathrm{C}_{2} \mathrm{H}_{2} \cdots \mathrm{AuCN} \cdots \mathrm{SiF}_{4}$ & 2.6100 & -0.2498 & -6.92 & -1.97 \\
$\mathrm{NCAu}^{2} \cdot \mathrm{C}_{2} \mathrm{H}_{4} \cdots \mathrm{SiF}_{4}$ & 3.5234 & 0.0354 & -1.65 & 0.28 \\
& & & &
\end{tabular}

cooperativity. The influence of $\pi \cdots$ metal interaction on the strength of tetrel bond is more prominent than that on halogen bond, where the increased percentage of interaction energy is less than $22 \%{ }^{57}$ When the four hydrogen atoms in $\mathrm{C}_{2} \mathrm{H}_{4}$ are replaced with electron-withdrawing group $\mathrm{CN}$, the tetrel bond is weakened in $\mathrm{C}_{2}(\mathrm{CN})_{4} \cdots \mathrm{MCN} \cdots \mathrm{SiF}_{4}$ and the largest weakening is found in $\mathrm{C}_{2}(\mathrm{CN})_{4} \cdots \mathrm{AgCN} \cdots \mathrm{SiF}_{4}$. In $\mathrm{NCAu}^{\cdots} \mathrm{C}_{2} \mathrm{H}_{4} \cdots \mathrm{SiF}_{4}$, where the middle molecule $\mathrm{C}_{2} \mathrm{H}_{4}$ plays a double Lewis base in the $\mathrm{Au} \cdots$ $\pi$ interaction and $\pi$-tetrel bond, a weakening effect is also found.
The change in the strength of tetrel bond is also estimated with the electron density at the intermolecular BCP (Table 6). Against the electron density at the $\mathrm{N}^{\cdots \mathrm{C}} \mathrm{BCP}$ is almost not changed in $\mathrm{C}_{2} \mathrm{H}_{4} \cdots \mathrm{AuCN} \cdots \mathrm{CF}_{4}$. The electron density of tetrel bond is increased in $\mathrm{C}_{2} \mathrm{H}_{4} \cdots \mathrm{MCN} \cdots \mathrm{TF}_{4}(\mathrm{M}=\mathrm{Cu}, \mathrm{Ag}$, and $\mathrm{Au} ; \mathrm{T}$ $=\mathrm{Si}, \mathrm{Ge}$, and $\mathrm{Sn})$ and $\mathrm{C}_{2} \mathrm{H}_{2} \cdots \mathrm{AuCN} \cdots \mathrm{SiF}_{4}$, while it is decreased in $\mathrm{C}_{2}(\mathrm{CN})_{4} \cdots \mathrm{MCN} \cdots \mathrm{SiF}_{4}$ and $\mathrm{NCAu}^{\cdots} \mathrm{C}_{2} \mathrm{H}_{4} \cdots \mathrm{SiF}_{4}$. With the change of tetrel bonding strength, its nature is also changed. For example, the tetrel bond has a nature of partially covalent interaction in $\mathrm{C}_{2} \mathrm{H}_{4} \cdots \mathrm{AuCN} \cdots \mathrm{SiF}_{4}$ and $\mathrm{C}_{2} \mathrm{H}_{2} \cdots \mathrm{AuCN} \cdots \mathrm{SiF}_{4}$, evidenced by the negative energy density, while it is a purely closeshell interaction in $\mathrm{C}_{2}(\mathrm{CN})_{4} \cdots \mathrm{MCN} \cdots \mathrm{SiF}_{4}$ and $\mathrm{NCAu}^{\cdots} \mathrm{C}_{2} \mathrm{H}_{4} \cdots$ $\mathrm{SiF}_{4}$, evidenced by the positive energy density.

Based on the dominant role of electrostatic interaction in the tetrel bond, it is natural to analyze the change of tetrel bonding strength in the triads with electrostatic potentials. Table 7 presents the most negative MEP on the $\mathrm{N}$ atom of MCN in $\pi \cdots$ MCN and on the $\mathrm{C}=\mathrm{C}$ bond in $\mathrm{NCAu} \cdots \mathrm{C}_{2} \mathrm{H}_{4}$. This value is more negative in $\mathrm{C}_{2} \mathrm{H}_{4} \cdots \mathrm{MCN}$ and $\mathrm{C}_{2} \mathrm{H}_{2} \cdots A$ AuCN with respect to MCN but is less negative in $\mathrm{C}_{2}(\mathrm{CN})_{4} \cdots \mathrm{MCN}$ and $\mathrm{NCAu}^{\cdots} \mathrm{C}_{2} \mathrm{H}_{4}$ with respect to MCN and $\mathrm{C}_{2} \mathrm{H}_{4}$. This shows that the former is a stronger Lewis base and the latter is a weaker Lewis base. As a result, the former forms a stronger tetrel bond and the latter forms a weaker tetrel bond.

The charge transfer of tetrel bond increases in $\mathrm{C}_{2} \mathrm{H}_{4} \cdots$ $\mathrm{MCN} \cdots \mathrm{TF}_{4}(\mathrm{M}=\mathrm{Cu}, \mathrm{Ag}$, and $\mathrm{Au} ; \mathrm{T}=\mathrm{Si}, \mathrm{Ge}$, and $\mathrm{Sn})$ and $\mathrm{C}_{2} \mathrm{H}_{2} \cdots$ AuCN $\cdots \mathrm{SiF}_{4}$ but decreases in $\mathrm{C}_{2}(\mathrm{CN})_{4} \cdots \mathrm{MCN}^{2} \cdots \mathrm{SiF}_{4}$ and $\mathrm{NCAu}^{\cdots} \mathrm{C}_{2} \mathrm{H}_{4} \cdots \mathrm{SiF}_{4}$ (Table $\left.\mathrm{S} 1 \dagger\right)$. The charge transfer has the largest increase in $\mathrm{C}_{2} \mathrm{H}_{4} \cdots \mathrm{CuCN} \cdots \mathrm{SiF}_{4}$ and the largest decrease in $\mathrm{C}_{2}(\mathrm{CN})_{4} \cdots \mathrm{AgCN} \cdots \mathrm{SiF}_{4}$. The relationship between the change of charge transfer and the change of interaction energy is shown in Fig. 5. They display a good linear relationship with a correlation coefficient of 0.987 . This indicates that charge transfer is also responsible for the change of tetrel bonding strength. Similarly, the orbital interaction has a similar change with the charge transfer.

Table 6 Electron density $\left(\rho_{\mathrm{b}}\right)$ and energy density $\left(H_{\mathrm{b}}\right)$ in the triads as well as the difference of electron density $\left(\Delta \rho_{\mathrm{b}}\right)$ relative to the corresponding dyads, all are in $\mathrm{au}^{a}$

\begin{tabular}{llll}
\hline Triads & $\rho_{\mathrm{b}}$ & $\Delta \rho_{\mathrm{b}}$ & $H_{\mathrm{b}}$ \\
\hline $\mathrm{C}_{2} \mathrm{H}_{4} \cdots \mathrm{AuCN} \cdots \mathrm{CF}_{4}$ & 0.0052 & 0.0002 & 0.0010 \\
$\mathrm{C}_{2} \mathrm{H}_{4} \cdots \mathrm{AuCN} \cdots \mathrm{SiF}_{4}$ & 0.0193 & 0.0070 & -0.0005 \\
$\mathrm{C}_{2} \mathrm{H}_{4} \cdots \mathrm{AuCN} \cdots \mathrm{GeF}_{4}$ & 0.0619 & 0.0092 & -0.0854 \\
$\mathrm{C}_{2} \mathrm{H}_{4} \cdots \mathrm{AuCN} \cdots \mathrm{SnF}_{4}$ & 0.0647 & 0.0047 & -0.0859 \\
$\mathrm{C}_{2} \mathrm{H}_{4} \cdots \mathrm{AgCN} \cdots \mathrm{SiF}_{4}$ & 0.0416 & 0.0102 & -0.0073 \\
$\mathrm{C}_{2} \mathrm{H}_{4} \cdots \mathrm{CuCN} \cdots \mathrm{SiF}_{4}$ & 0.0351 & 0.0170 & -0.0096 \\
$\mathrm{C}_{2}(\mathrm{CN})_{4} \cdots \mathrm{AuCN} \cdots \mathrm{SiF}_{4}$ & 0.0105 & -0.0018 & 0.0011 \\
$\mathrm{C}_{2}(\mathrm{CN})_{4} \cdots \mathrm{AgCN} \cdots \mathrm{SiF}_{4}$ & 0.0135 & -0.0179 & 0.0008 \\
$\mathrm{C}_{2}(\mathrm{CN})_{4} \cdots \mathrm{CuCN} \cdots \mathrm{SiF}_{4}$ & 0.0107 & -0.0074 & 0.0010 \\
$\mathrm{C}_{2} \mathrm{H} \mathrm{H}_{2} \cdots \mathrm{AuCN} \cdots \mathrm{SiF}_{4}$ & 0.0187 & 0.0064 & -0.0003 \\
$\mathrm{NCAu} \cdots \mathrm{C}_{2} \mathrm{H}_{4} \cdots \mathrm{SiF}_{4}$ & 0.0050 & 0.0200 & 0.0011
\end{tabular}

${ }^{a}$ Note: the bond path is $\mathrm{N} \cdots \mathrm{F}$ in most complexes, but $\mathrm{N} \cdots \mathrm{T}$ in $\mathrm{C}_{2} \mathrm{H}_{4} \cdots$ AuCN $\cdots \mathrm{GeF}_{4}, \mathrm{C}_{2} \mathrm{H}_{4} \cdots \mathrm{AuCN} \cdots \mathrm{SnF}_{4}$, and $\mathrm{C}_{2} \mathrm{H}_{4} \cdots \mathrm{AgCN} \cdots \mathrm{SiF}_{4}$, and $\mathrm{C} \cdots \mathrm{F}$ in $\mathrm{NCAu}^{\cdots} \mathrm{C}_{2} \mathrm{H}_{4} \cdots \mathrm{SiF}_{4}$. All are average values for the $\mathrm{N} \cdots \mathrm{F}$ and $\mathrm{C} \cdots \mathrm{F}$ paths. 
Table 7 The most negative MEP $\left(V_{\min }\right)$ on the $\mathrm{N}$ atom of $\mathrm{MCN}$ in $\pi \cdots$ MCN dyads and on the $\mathrm{C}=\mathrm{C}$ bond in $\mathrm{NCAu} \cdots \mathrm{C}_{2} \mathrm{H}_{4}$ as well as its difference $\left(\Delta V_{\text {min }}\right)$ relative to the corresponding monomers, all are in $\mathrm{kcal} \mathrm{mol}^{-1}$

\begin{tabular}{lll}
\hline Dyads & $V_{\min }$ & $\Delta V_{\min }$ \\
\hline $\mathrm{C}_{2} \mathrm{H}_{4} \cdots \mathrm{CuCN}$ & -57.72 & -3.77 \\
$\mathrm{C}_{2} \mathrm{H}_{4} \cdots \mathrm{AgCN}$ & -59.36 & -3.84 \\
$\mathrm{C}_{2} \mathrm{H}_{4} \cdots \mathrm{AuCN}$ & -54.58 & -5.90 \\
$\mathrm{C}_{2}(\mathrm{CN})_{4} \cdots \mathrm{CuCN}$ & -43.90 & 10.05 \\
$\mathrm{C}_{2}(\mathrm{CN})_{4} \cdots \mathrm{AgCN}$ & -47.86 & 7.66 \\
$\mathrm{C}_{2}(\mathrm{CN})_{4} \cdots \mathrm{AuCN}$ & -38.88 & 9.80 \\
$\mathrm{C}_{2} \mathrm{H}_{2} \cdots \mathrm{AuCN}$ & -54.14 & -5.46 \\
$\mathrm{NCAu} \cdots \mathrm{C}_{2} \mathrm{H}_{4}$ & 18.70 & 35.78 \\
& &
\end{tabular}

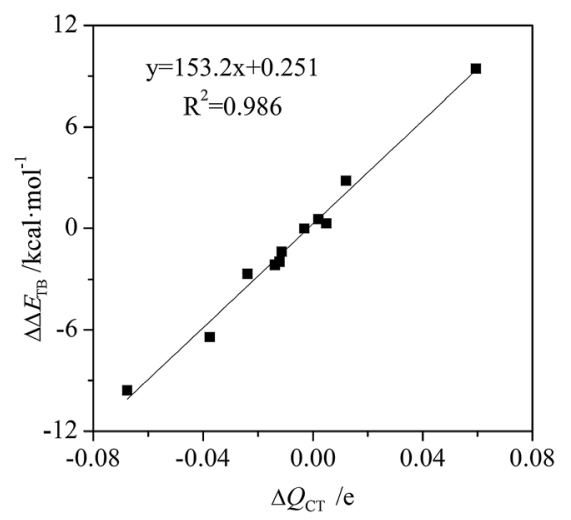

Fig. 5 Change of charge transfer $\left(\Delta Q_{C T}\right)$ versus change of interaction energy $(\Delta \Delta E)$.

Table $\mathrm{S} 2 \uparrow$ presents the energy components of the tetrel bond in the triads to have a further insight into the origin of its interaction energy change. In most interactions, the main attractive contributions are from electrostatic and polarization, thus only their change is depicted in Fig. 6. For $\mathrm{C}_{2} \mathrm{H}_{4} \cdots \mathrm{MCN} \cdots$

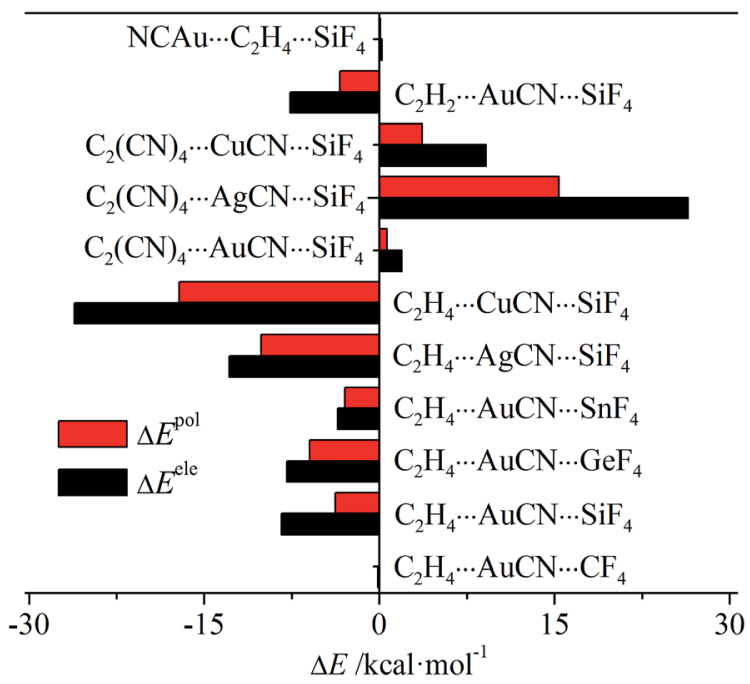

Fig. 6 Change of electrostatic and polarization energies in the triads relative to the respective dyads.
$\mathrm{TF}_{4}(\mathrm{M}=\mathrm{Cu}, \mathrm{Ag}$, and $\mathrm{Au} ; \mathrm{T}=\mathrm{Si}, \mathrm{Ge}$, and $\mathrm{Sn})$ and $\mathrm{C}_{2} \mathrm{H}_{2} \cdots \mathrm{AuCN} \cdots$ $\mathrm{SiF}_{4}$, both terms are more negative, while they are more positive in $\mathrm{C}_{2}(\mathrm{CN})_{4} \cdots \mathrm{MCN} \cdots \mathrm{SiF}_{4}$ and $\mathrm{NCAu}^{\cdots} \mathrm{C}_{2} \mathrm{H}_{4} \cdots \mathrm{SiF}_{4}$. This indicates that both terms have important contributions in tuning the strength of tetrel bond through cooperativity. In all systems, electrostatic has the larger change than polarization, showing the larger contribution from electrostatic. Both terms are almost not changed in $\mathrm{C}_{2} \mathrm{H}_{4} \cdots A$ AuCN $\cdots \mathrm{CF}_{4}$ and $\mathrm{NCAu} \cdots \mathrm{C}_{2} \mathrm{H}_{4} \cdots$ $\mathrm{SiF}_{4}$, consistent with the small change of interaction energy in both triads.

\section{Conclusions}

The triads of $\mathrm{C}_{2} \mathrm{H}_{4} \cdots \mathrm{AuCN} \cdots \mathrm{TF}_{4}(\mathrm{~T}=\mathrm{C}, \mathrm{Si}, \mathrm{Ge}$, and $\mathrm{Sn}), \mathrm{C}_{2} \mathrm{H}_{4} \cdots$ $\mathrm{MCN} \cdots \mathrm{SiF}_{4}(\mathrm{M}=\mathrm{Cu}, \mathrm{Ag}$, and $\mathrm{Au}), \mathrm{C}_{2}(\mathrm{CN})_{4} \cdots \mathrm{MCN} \cdots \mathrm{SiF}_{4}$, $\mathrm{C}_{2} \mathrm{H}_{2} \cdots$ AuCN $\cdots \mathrm{SiF}_{4}$, and $\mathrm{NCAu} \mathrm{C}_{2} \mathrm{H}_{4} \cdots \mathrm{SiF}_{4}$ as well as their dyads have been studied. The following conclusions are reached.

(1) Coin metal substituents have a prominent enhancing effect on the strength of tetrel bond. This enhancing effect is related with the nature of coin metal and tetrel atoms, which is larger in the order $\mathrm{C}<\mathrm{Si}<\mathrm{Ge}<\mathrm{Sn}$ and $\mathrm{Au}<\mathrm{Cu}<\mathrm{Ag}$. The tetrel bond varies from a weak interaction in $\mathrm{HCN} \cdots \mathrm{SiF}_{4}$ $\left(-3.45 \mathrm{kcal} \mathrm{mol}^{-1}\right)$ to a strong one in $\mathrm{AgCN} \cdots \mathrm{SiF}_{4}$ $\left(-15.80 \mathrm{kcal} \mathrm{mol}^{-1}\right)$.

(2) A $\pi \cdots$ metal interaction can regulate the strength of tetrel bond. The tetrel bond is strengthened in $\mathrm{C}_{2} \mathrm{H}_{4} \cdots \mathrm{AuCN} \cdots \mathrm{TF}_{4}(\mathrm{~T}$ $=\mathrm{C}, \mathrm{Si}$, Ge, and $\mathrm{Sn}), \mathrm{C}_{2} \mathrm{H}_{4} \cdots \mathrm{MCN} \cdot \mathrm{SiF}_{4}(\mathrm{M}=\mathrm{Cu}, \mathrm{Ag}$, and $\mathrm{Au})$, and $\mathrm{C}_{2} \mathrm{H}_{2} \cdots \mathrm{AuCN} \cdots \mathrm{SiF}_{4}$ but is weakened in $\mathrm{C}_{2}(\mathrm{CN})_{4} \cdots \mathrm{MCN} \cdots$ $\mathrm{SiF}_{4}$ and $\mathrm{NCAu} \cdots \mathrm{C}_{2} \mathrm{H}_{4} \cdots \mathrm{SiF}_{4}$. Accompanied with the strengthening/weakening of tetrel bond, its nature could also be changed.

\section{Conflicts of interest}

There are no conflicts to declare.

\section{Acknowledgements}

This work was supported by the National Natural Science Foundation of China (21573188) and the Shandong Province Natural Science Foundation (ZR2016BL11).

\section{References}

1 T. Clark, M. Hennemann, J. S. Murray and P. Politzer, J. Mol. Model., 2007, 13, 291-296.

2 P. Politzer, P. Lane, M. C. Concha, Y. Ma and J. S. Murray, J. Mol. Model., 2007, 13, 305-311.

3 J. S. Murray, P. Lane, T. Clark and P. Politzer, J. Mol. Model., 2007, 13, 1033-1038.

4 J. S. Murray, P. Lane and P. Politzer, J. Mol. Model., 2009, 15, 723-729.

5 P. Politzer, J. S. Murray and P. Lane, Int. J. Quantum Chem., 2007, 107, 3046-3052.

6 A. Bauzá, T. J. Mooibroek and A. Frontera, Angew. Chem., Int. Ed., 2013, 52, 12317-12321. 
7 S. Zahn, R. Frank, E. Hey-Hawkins and B. Kirchner, Chem.Eur. J., 2011, 17, 6034-6038.

8 W. Z. Wang, B. M. Ji and Y. Zhang, J. Phys. Chem. A, 2009, 113, 8132-8135.

9 P. Politzer, J. S. Murray and P. Lane, Phys. Chem. Chem. Phys., 2013, 15, 11178-11189.

10 S. J. Grabowski and W. A. Sokalski, ChemPhysChem, 2017, 18, 1569-1577.

11 D. P. de Sousa, C. Wegeberg, M. S. Vad, S. Mørup, C. Frandsen, W. A. Donald and C. J. McKenzie, Chem.-Eur. J., 2016, 22, 3810-3820.

12 S. P. Thomas, K. Satheeshkumar, G. Mugesh and T. N. G. Row, Chem.-Eur. J., 2015, 21, 6793-6800.

13 A. R. Voth, F. A. Hays and P. S. Ho, Proc. Natl. Acad. Sci. U. S. A., 2007, 114, 6188-6193.

14 S. J. Grabowski, Phys. Chem. Chem. Phys., 2014, 16, 18241834.

15 M. X. Liu, Q. Z. Li, J. B. Cheng, W. Z. Li and H. B. Li, J. Chem. Phys., 2016, 145, 224310.

16 D. Mani and E. Arunan, Phys. Chem. Chem. Phys., 2013, 15, 14377-14383.

17 S. P. Thomas, M. S. Pavan and T. N. G. Row, Chem. Commun., 2014, 50, 49-51.

18 Q. Z. Li, X. Guo, X. Yang, W. Z. Li, J. B. Cheng and H. B. Li, Phys. Chem. Chem. Phys., 2014, 16, 11617-11625.

19 A. Bauzá, T. J. Mooibroek and A. Frontera, Chem. Commun., 2014, 50, 12626-12629.

20 S. Scheiner, J. Phys. Chem. A, 2015, 119, 9189-9199.

21 Q. Z. Li, H. Y. Zhuo, H. B. Li, Z. B. Liu, W. Z. Li and J. B. Cheng, J. Phys. Chem. A, 2015, 119, 2217-2224.

22 X. Guo, Y. W. Liu, Q. Z. Li, W. Z. Li and J. B. Cheng, Chem. Phys. Lett., 2015, 620, 7-12.

23 A. Bauzá, A. Frontera and T. J. Mooibroek, Phys. Chem. Chem. Phys., 2016, 18, 1693-1698.

24 V. de P. N. Nziko and S. Scheiner, Phys. Chem. Chem. Phys., 2016, 18, 3581-3590.

25 Q. C. Wei, Q. Z. Li, J. B. Cheng, W. Z. Li and H. B. Li, $R S C$ Adv., 2016, 6, 79245-79253.

26 M. X. Liu, Q. Z. Li and S. Scheiner, Phys. Chem. Chem. Phys., 2017, 19, 5550-5559.

27 S. Scheiner, J. Phys. Chem. A, 2017, 121, 3606-3615.

28 S. Scheiner, Chem.-Eur. J., 2016, 22, 18850-18858.

29 J. S. Murray, P. Lane, T. Clark, K. E. Riley and P. Politzer, J. Mol. Model., 2012, 18, 541-548.

30 S. Scheiner, J. Phys. Chem. A, 2017, 121, 5561-5568.

31 J. B. Cheng, R. Li, Q. Z. Li, B. Jing, Z. B. Liu, W. Z. Li, B. A. Gong and J. Z. Sun, J. Phys. Chem. A, 2010, 114, 10320-10325.

32 S. Scheiner, J. Phys. Chem. A, 2017, 121, 3606-3615.

33 G. Mahmoudi, A. Bauzá and A. Frontera, Dalton Trans., 2016, 45, 4965-4969.

34 G. Mahmoudi, A. Bauzá, M. Amini, E. Molins, J. T. Mague and A. Frontera, Dalton Trans., 2016, 45, 10708-10716.

35 M. S. Gargari, V. Stilinović, A. Bauzá, A. Frontera, P. McArdle, D. V. Derveer, S. W. Ng and G. Mahmoudi, Chem.-Eur. J., 2015, 21, 17951-17958.
36 M. X. Liu, Q. Z. Li, W. Z. Li and J. B. Cheng, J. Mol. Graphics Modell., 2016, 65, 35-42.

37 M. X. Liu, L. Yang, Q. Z. Li, W. Z. Li, J. B. Cheng, B. Xiao and X. F. Yu, J. Mol. Model., 2016, 22, 192.

38 Q. J. Tang and Q. Z. Li, Comput. Theor. Chem., 2014, 1050, 5157.

39 M. D. Esrafili, N. Mohammadirad and M. Solimannejad, Chem. Phys. Lett., 2015, 628, 16-20.

40 S. Yourdkhani, T. Korona and N. L. Hadipour, J. Comput. Chem., 2015, 36, 2412-2428.

41 M. Marín-Luna, I. Alkorta and J. Elguero, J. Phys. Chem. A, 2016, 120, 648-656.

42 W. Li, Y. Zeng, X. Li, Z. Sun and L. Meng, Phys. Chem. Chem. Phys., 2016, 18, 24672-24680.

43 H. L. Xu, J. B. Cheng, X. Yang, Z. B. Liu, B. Xiao and Q. Z. Li, RSC Adv., 2017, 7, 21713-21720.

44 H. L. Xu, J. B. Cheng, X. Yang, Z. B. Liu, W. Z. Li and Q. Z. Li, ChemPhysChem, 2017, 18, 2442-2450.

45 M. J. S. Dewar and G. P. Ford, J. Am. Chem. Soc., 1979, 101, 783-791.

46 D. Feller, J. Comput. Chem., 1996, 17, 1571-1586.

47 S. F. Boys and F. Bernardi, Mol. Phys., 1970, 19, 553-566.

48 M. J. Frisch, G. W. Trucks, H. B. Schlegel, G. E. Scuseria, M. A. Robb, J. R. Cheeseman, G. Scalmani, V. Barone, B. Mennucci, G. A. Petersson, H. Nakatsuji, M. Caricato, X. Li, H. P. Hratchian, A. F. Izmaylov, J. Bloino, G. Zheng, J. L. Sonnenberg, M. Hada, M. Ehara, K. Toyota, R. Fukuda, J. Hasegawa, M. Ishida, T. Nakajima, Y. Honda, O. Kitao, H. Nakai, T. Vreven, J. J. A. Montgomery, J. E. Peralta, F. Ogliaro, M. Bearpark, J. J. Heyd, E. Brothers, K. N. Kudin, V. N. Staroverov, R. Kobayashi, J. Normand, K. Raghavachari, A. Rendell, J. C. Burant, S. S. Iyengar, J. Tomasi, M. Cossi, N. Rega, J. M. Millam, M. Klene, J. E. Knox, J. B. Cross, V. Bakken, C. Adamo, J. Jaramillo, R. Gomperts, R. E. Stratmann, O. A. Yazyev, J. Austin, R. Cammi, C. Pomelli, J. W. Ochterski, R. L. Martin, K. Morokuma, V. G. Zakrzewski, G. A. Voth, P. Salvador, J. J. Dannenberg, S. A. Dapprich, D. Daniels, O. Farkas, J. B. Foresman, J. V. Ortiz, J. Cioslowski and D. J. Fox, Gaussian 09, Revision A.02, Gaussian, Inc., Wallingford, CT, 2009.

49 F. Bulat, A. Toro-Labbé, T. Brinck, J. Murray and P. Politzer, J. Mol. Model., 2010, 16, 1679-1691.

50 R. F. W. Bader, Atoms in Molecules: A Quantum Theory, Clarendon Press, Oxford, 1990.

51 R. F. W. Bader, AIM2000 Program, v. 2.0, McMaster University, Hamilton, Canada, 2000.

52 A. E. Reed, L. A. Curtiss and F. Weinhold, Chem. Rev., 1988, 88, 899-926.

53 M. W. Schmidt, K. K. Baldridge, J. A. Boatz, S. T. Elbert, M. S. Gordon, J. H. Jensen, S. Koseki, N. Matsunaga, K. A. Nguyen, S. J. Su, T. L. Windus, M. Dupuis and J. A. Montgomery, J. Comput. Chem., 1993, 14, 1347-1363.

54 P. F. Su and H. Li, J. Chem. Phys., 2009, 13, 014102.

55 X. Wu, Z. Qin, H. Xie, R. Cong, X. Wu, Z. Tang and H. Fan, J. Phys. Chem. A, 2010, 114, 12839-12844. 
56 W. D. Arnold and E. Oldfield, J. Am. Chem. Soc., 2000, 122, 58 W. K. Tian, X. Huang, Q. Z. Li, W. Z. Li, J. B. Cheng and 12835-12841.

B. A. Gong, J. Mol. Model., 2013, 19, 1311-1318.

57 M. Gao, J. B. Cheng, X. Yang, W. Z. Li, B. Xiao and Q. Z. Li, J. 59 D. Mani and E. Arunan, J. Phys. Chem. A, 2014, 118, 10081Chem. Phys., 2015, 143, 054308. 10089. 